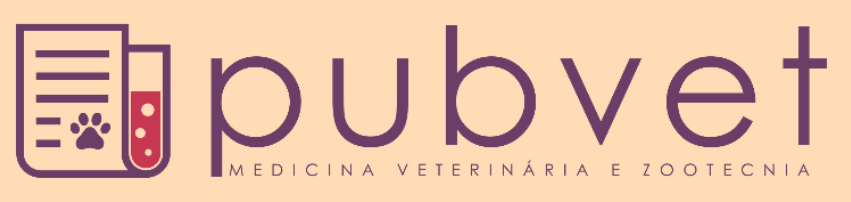

https://doi.org/10.31533/pubvet.v14n5a578.1-7

\title{
Detecção de resíduos de antibióticos em leite cru em fazendas de Aquidabã - Sergipe
}

\author{
Rafael Nascimento Garcez de Carvalho', Anne Caroline Leite Andrade Santos de \\ Oliveira $^{10}$, João Pedro Araújo Azevedo Silva ${ }^{10}$, Caio Filipe Carvalho dos Anjos ${ }^{10}$, \\ Erika Souza Vieira $^{2 * 0}$
}

${ }^{1}$ Discente do curso de medicina veterinária na Faculdade Pio Décimo. Aracaju-SE, Brasil.
${ }^{2}$ Farmacêutica, professora de bioquímica aplicada na faculdade Pio Décimo. Aracaju-SE, Brasil.
*Autora para correspondência, E-mail: souza-erika@ @otmail.com

Resumo. O leite lidera o ranking de produto de origem animal mais consumido do mundo por ser o mais completo in natura. É um produto oriundo da ordenha completa ininterrupta em condições de higiene de vacas sadias bem alimentadas e descansadas. Durante o processo de produção podem passar medicamentos ou drogas veterinárias que foram administradas às vacas para o controle de alguma doença, como é o caso dos antibióticos que atuam sobre micro-organismos responsáveis pelas doenças infecciosas. A refrigeração e os processamentos realizados nos laticínios não são capazes de eliminar os possíveis resíduos de antibióticos existentes no leite, adquiridos pela administração de medicamentos veterinários em tratamentos do gado leiteiro. Além de interferir em análises laboratoriais utilizadas como rotina em laticínios, esses resíduos apresentam riscos à saúde humana, causando um efeito adverso na flora intestinal, podendo prejudicar sua ação gastromucoprotetora, além de propiciar a seleção de populações de bactérias altamente resistentes. O presente trabalho teve como objetivo realizar uma pesquisa de campo em seis propriedades localizadas no município de Aquidabã - Se e avaliar a ocorrência de resíduos de antibióticos em amostras do leite in natura utilizando o teste TwinSensor BT ${ }^{\circledR}$ nestas propriedades. A aplicação dos questionários e coleta das amostras de leite foi realizada no mês de outubro de 2017. Os resultados do questionário mostraram que os proprietários não conhecem os antibióticos pelo nome do princípio ativo e sim pelo nome comercial, a prescrição ainda é feita na maioria por vendedores de lojas agropecuárias e durante a utilização destes medicamentos o destino do leite é sempre a comercialização e no tocante a análise de resíduos de antibióticos todas as amostras foram negativas para a tetraciclina e as amostras de uma propriedade foi positiva para $\beta$-lactâmicos.

Palavras chave: antibiótico, leite, Sergipe, TwinSensor BT ${ }^{\circledR}$

\section{Detention of antibiotic residues in raw milk in farms of Aquidabã -Sergipe}

Abstract. Milk more leads ranking of product of animal origin consumed of the world for being most complete in natura. It is a deriving product of milks complete interrupta in conditions of hygiene of fed and well rested healthy cows. During the production process they can pass medicines or drugs veterinarians who had been managed to the cows for the control of some illness, as it is the case of the antibiotics that act on responsible microorganisms for the infectious illnesses. The refrigeration and the processings carried through in the laticínios are not capable to eliminate the possible existing antibiotic residues in milk, acquired for the medicine administration veterinarians in treatments of the milk cattle. Beyond intervening with used laboratoriais analyses as routine in laticínios, these residues present risks to the health human being, causing an adverse effect in the intestinal 
flora, being able to harm its gastromucoprotetora action, beyond propitiating the election of populations of highly resistant bacteria. The present work had as objective to carry through a research of field in six properties located in the city of Aquidabã-If and to evaluate the occurrence of antibiotic residues in samples of milk in natura being used the test TwinSensor $\mathrm{BT}^{\circledR}$ in these properties. The application of the questionnaires and collects of the milk samples was carried through in the month of October of 2017. The results of the questionnaire had shown that the proprietors do not know antibiotics for the name of the active principle and yes for the corporate name, the lapsing still is made in the majority for salesmen of farming store and during the use of these medicines the destination of milk is always the commercialization and in regards to analysis of antibiotic residues all the samples had been negative for the tetraciclina and the samples of a property were positive for $\beta$-lactâmicos.Resumo em inglês. A palavra abstract em maiúsculo e negrito.

Keywords: antibiotic, milk, sergipe, TwinSensor $\mathrm{BT}^{\circledR}$

\section{Introdução}

O leite é proveniente da glândula mamária de mamíferos sadios durante o período de lactação (Porto et al., 2009). É o produto oriundo da ordenha completa e ininterrupta, em condições de higiene de vacas sadias, bem alimentadas e descansadas. Qualquer tipo de agressão causada na glândula por traumas físicos ou outros tipos de agentes como micro-organismos, substâncias químicas irritantes, podem desencadear um processo inflamatório denominado de mastite (Fagan et al., 2010), sendo esta a principal doença do gado leiteiro que requer antibioticoterapia, portanto, é uma das principais origens de resíduos de antibióticos no leite, seguida da diarreia e tratamento de Babesia, além de serem utilizados como suplemento dietético.

A presença de resíduos de antibióticos no leite pode provocar graves problemas de saúde no consumidor, entre os quais: hipersensibilidade, choque anafilático em indivíduos alérgicos, teratogenia, resistência microbiana e desequilíbrio da microbiota intestinal, e ainda, desencadeando prejuízos financeiros na indústria, por interferirem na inibição de microrganismos benéficos na produção de derivados do leite (Costa, 1996). Para detectar a presença de resíduos de medicamentos veterinários no leite e em seus derivados, existem vários testes qualitativos e quantitativos disponíveis no mercado (Araujo et al., 2015). Estes testes podem ser classificados de acordo com seu princípio ou mecanismo de ação em inibição de crescimento bacteriano, imunológicos, enzimáticos e cromatografia líquida de alta eficiência. Em função do exposto, é evidente que para maior segurança no consumo de leite de boa qualidade, é necessário a conscientização de produtores e participação dos mesmos no que se refere ao período de carência ou descarte do leite quando necessário (Leira et al., 2018).

Neste trabalho foi realizada uma pesquisa de campo objetivando avaliar a ocorrência de resíduos de antibióticos em leite in natura em propriedades localizadas no município de Aquidabã - SE, através de testes de resíduos de antibióticos TwinSensor $\mathrm{BT}^{\circledR}$.

\section{Material e métodos}

Para a realização deste trabalho foram pesquisadas seis propriedades localizadas no município de Aquidabã - Sergipe, o qual está localizado na mesorregião do Agreste Sergipano, distante da capital Aracaju $98 \mathrm{~km}$. As amostras coletadas foram armazenadas em frascos plásticos mantidos sob refrigeração e conduzidos para análises que foram realizadas no mês de outubro de 2017 no laboratório de análise de leite do Laticínio Ponta Verde localizado no Povoado São Vicente no município de Propriá - Sergipe utilizando o kit de detecção de resíduos de antibióticos TwinSensor BT ${ }^{\circledR}$.

Esta pesquisa se caracteriza por ter sido realizada diretamente no campo, no período de agosto a outubro de 2017 para a coleta dos dados primários. Os dados primários foram obtidos pela aplicação de técnicas padronizadas de coleta de dados, tais como: amostragem e mensuração de resíduos de antibióticos; formulário de pesquisa e observação, permitindo registrar e analisar os dados de forma qualitativa e quantitativa. Os dados secundários foram explorados pela revisão de artigos, documentos e literaturas especializadas possibilitando, além de maior familiaridade com o problema a verificação dos resultados obtidos durante a realização desse trabalho. 
Para a determinação do número de amostras foi utilizado um plano de Amostragem Simples, com nível de inspeção GI de acordo com a Tabela de Codificação de Amostragem e a de Plano de Amostragem simples normal (Figuras 1 e 2) segundo a norma: Planos de amostragem e procedimentos na inspeção por atributos (NBR 5426, 1985).

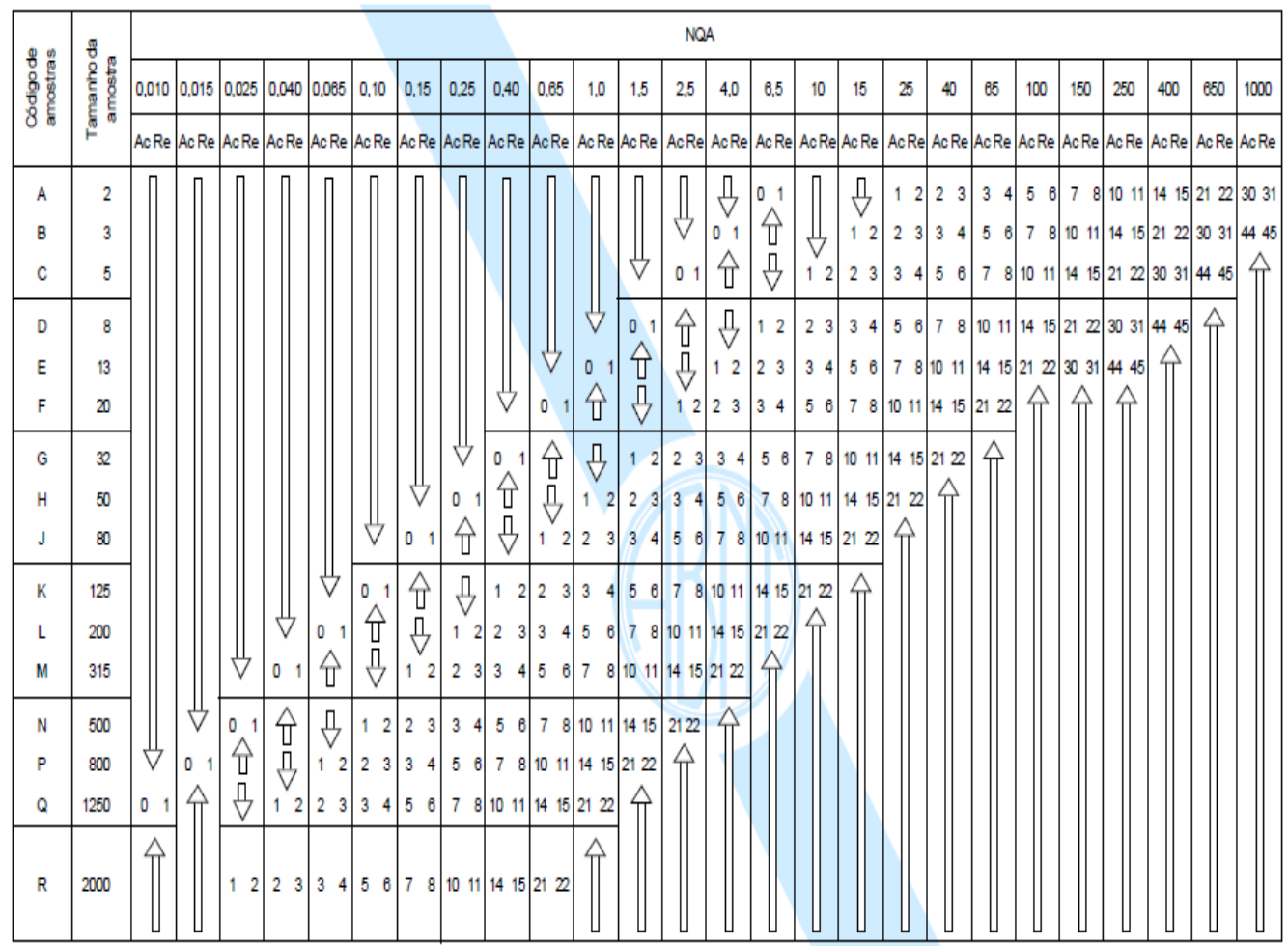

Figura 1. Plano de Amostragem simples normal. Fonte: NBR 5426, 1985.

\begin{tabular}{|c|c|c|c|c|c|c|c|c|}
\hline \multirow{2}{*}{\multicolumn{2}{|c|}{ Tamanho do lote }} & \multicolumn{4}{|c|}{ Niveis especiais de inspeção } & \multicolumn{3}{|c|}{ Niveis gerais de inspeção } \\
\hline & & \multirow{2}{*}{$\frac{\text { S1 }}{\text { A }}$} & \multirow{2}{*}{$\frac{S 2}{A}$} & \multirow{2}{*}{$\frac{\mathrm{S} 3}{\mathrm{~A}}$} & \multirow{2}{*}{$\frac{\mathrm{S} 4}{\mathrm{~A}}$} & \multirow{2}{*}{$\frac{1}{A}$} & \multirow[b]{2}{*}{ A } & \multirow{2}{*}{$\frac{\text { III }}{\text { B }}$} \\
\hline 2 & a & & & & & & & \\
\hline 9 & 15 & A & A & A & A & A & B & C \\
\hline 16 & 25 & A & A & B & B & B & C & D \\
\hline 26 & 50 & A & B & B & C & C & D & E \\
\hline 51 & 90 & B & B & C & C & C & E & $\mathrm{F}$ \\
\hline 91 & 150 & B & B & C & D & D & $\mathrm{F}$ & G \\
\hline 151 & 280 & B & C & D & E & E & G & $\mathrm{H}$ \\
\hline 281 & 500 & B & C & D & E & $\mathrm{F}$ & $\mathrm{H}$ & $\mathrm{J}$ \\
\hline 501 & 1200 & C & c & $\mathrm{E}$ & $\mathrm{F}$ & G & $J$ & $\mathrm{~K}$ \\
\hline 1201 & 3200 & c & D & $\mathrm{E}$ & G & $\mathrm{H}$ & $\mathrm{K}$ & L \\
\hline 3201 & 10000 & C & D & $\mathrm{F}$ & G & $\mathrm{J}$ & L & M \\
\hline 10001 & 35000 & c & D & $\mathrm{F}$ & $\mathrm{H}$ & $\mathrm{K}$ & M & $\mathrm{N}$ \\
\hline 35001 & 150000 & D & $\mathrm{E}$ & G & $\mathrm{J}$ & $\mathrm{L}$ & $\mathrm{N}$ & $\mathrm{P}$ \\
\hline 150001 & 500000 & D & E & G & $J$ & M & $\mathrm{P}$ & $\mathrm{Q}$ \\
\hline \multicolumn{2}{|c|}{ Acima de 500001} & D & E & $\mathrm{H}$ & $\mathrm{K}$ & $\mathrm{N}$ & Q & $\mathrm{R}$ \\
\hline
\end{tabular}

Figura 2. Tabela de Codificação de Amostragem. Fonte: NBR 5426, 1985. 
O número de amostras com nível geral de inspeção 1 e um lote total de 200 vacas foi igual a 13. Optou-se por um número de amostras igual a 18 para que a quantidade de amostras fosse a mesma para todas as propriedades (Figuras 1 e 2). Paralelamente à coleta procedeu-se a aplicação de um questionário, junto aos proprietários com o intuito de identificar se há ou não a utilização de antibióticos nas propriedades, quais os antibióticos utilizados, bem como os motivos da sua utilização e o destino do leite produzido.

Como ao chegar às propriedades a maior parte das vacas já haviam sido ordenhadas, o leite utilizado na amostragem foi retirado diretamente das vacas quando houve essa possibilidade ou diretamente dos tanques de refrigeração e as amostras foram acondicionadas em recipientes plásticos e mantidas sob refrigeração (Figura 3) durante o transporte até o laticínio Ponta Verde, localizado na zona rural do município de Propriá - Se, distante 42 km do município de Aquidabã.

No laticínio as amostras foram transferidas para o laboratório, onde as análises de resíduos de antibióticos foram realizadas utilizando o Teste Comercial TwinSensor BT ${ }^{\circledR}$ (Kit contendo teste rápido para detecção simultânea de resíduos de antibióticos dos grupos $\beta$-lactâmicos e tetraciclinas em leite, fabricado pela Unisensor, Bélgica), Figura 4.

Para a execução da análise foram adicionados $200 \mu 1$ de leite no micro tubo o qual foi misturado até obtenção de uma amostra homogênea. Em seguida as amostras foram incubadas por 6 minutos a $40^{\circ} \mathrm{C}$ para só então submergir a tira reativa no micro tubo e a incubação foi mantida por um tempo de 3 minutos até a visualização das linhas coloridas que surgem na tira (Figura 5).

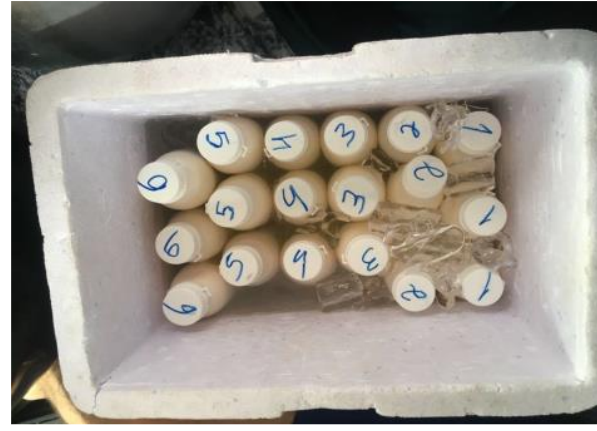

Figura 3. Frascos contendo amostras acondicionados para o transporte

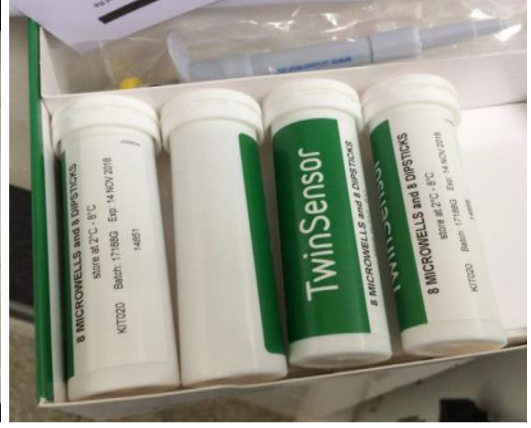

Figura 4. Teste Comercial TwinSensor $\mathrm{BT}^{\circledR}$

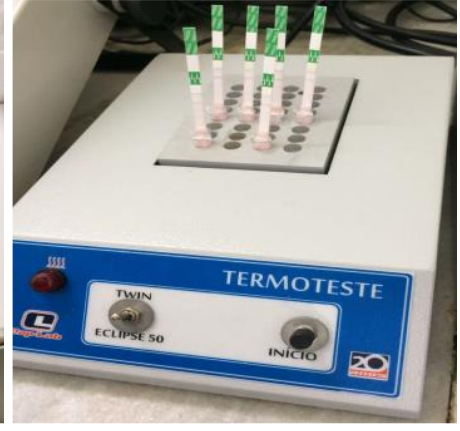

Figura 5. Amostras incubadas com a fita teste

\section{Resultados e discussão}

As propriedades estudadas no município de Aquidabã - Sergipe foram caracterizadas como de pequeno porte com quantitativo de rebanho médio de 30 cabeças. Na entrevista com o proprietário ou responsável pela propriedade, quando a pergunta foi sobre a utilização de antibióticos no seu rebanho, dos seis entrevistados $83 \%$ não responderam a esta pergunta e $17 \%$ respondeu que não utilizavam este tipo de medicamento (Gráfico 1). Isso pode ter ocorrido por uma falha do entrevistador ou por medo ou receio dos produtores uma vez que o leite produzido nessas propriedades é destinado a pequenos laticínios (66\%) ou ao laticínio Sabe Alimentos Ltda, que é um grande laticínio da região (17\%) e outros $17 \%$ não quiseram responder, conforme pode ser observado no gráfico 2.

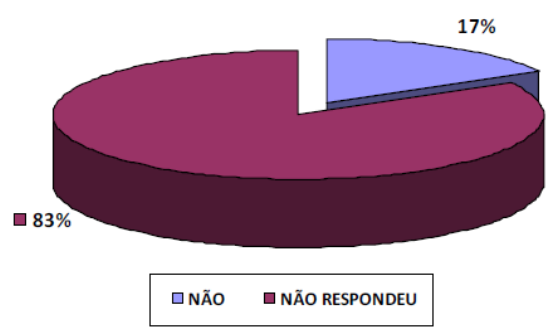

Gráfico 1. Utilização de antibióticos no rebanho
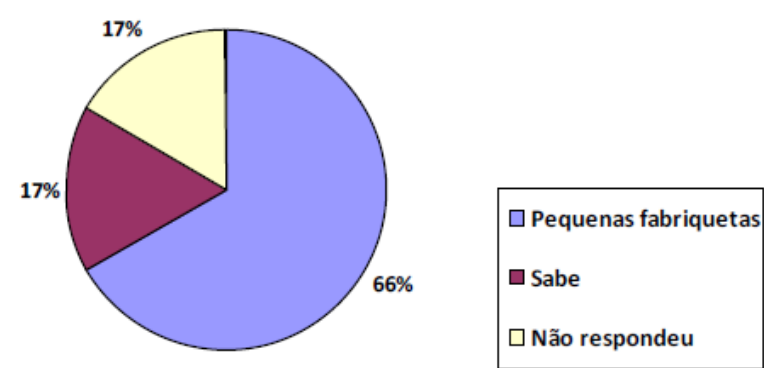

Gráfico 2. Destino do leite produzido 
Apesar de responderem "Não" ou não responderem em relação a utilização de antibióticos, quando a pergunta se refere ao motivo para a utilização dos mesmos o tratamento de mastite e diarreia são apontados como os maiores motivos (28\% para ambos) seguido de $22 \%$ para anemia e machucaduras, conforme mostra o gráfico 3.

Apesar de não ter respondido no questionário quais os antibióticos utilizados, em conversa durante a aplicação dos mesmos o proprietário e/ou gerente da propriedade acabou relatando a utilização de vários medicamentos, entre eles antibióticos que estão listados na tabela 1.

Considerando a maior utilização para a mastite, estes medicamentos são destinados às vacas secas (50\%), vacas recém-paridas (33\%) e vacas de alta produção (17\%) conforme apresentado no Gráfico 4. Esses dados confirmam o que foi observado por Erskine et al. (2002) e Korb et al. (2011).

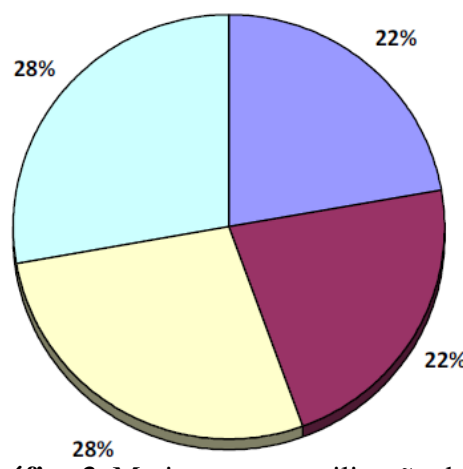

Gráfico 3. Motivos para a utilização de antibióticos

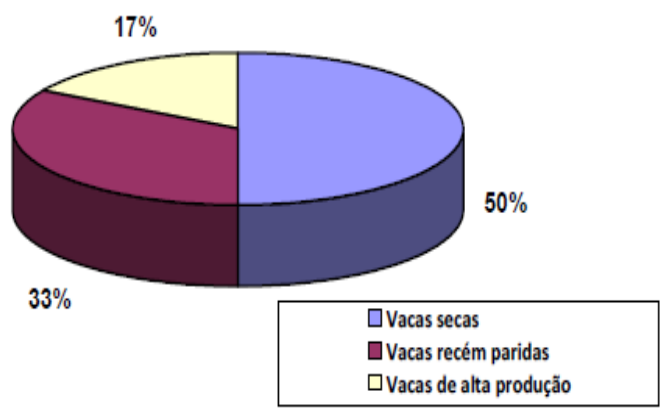

Gráfico 4. Vacas que utilizam antibióticos

Apesar dos entrevistados afirmarem que a via de administração escolhida para os antibióticos é a via intramuscular, percebe-se a utilização da via intramamária quando eles afirmam a utilização do Mastifin $^{\circledR}$ e o Gentatec ${ }^{\circledR} 250 \mathrm{mg}$, ambos apresentam sulfato de gentamicina na sua formulação.

Tabela 1. Antibióticos utilizados nas seis propriedades pesquisadas no município de Aquidabã - Sergipe durante o período de agosto a outubro de 2017

\begin{tabular}{lll}
\hline Antibiótico & \multicolumn{1}{c}{ Formulação } & $10.000 .000 \mathrm{UI}$ \\
& & \\
Pencivet & Benzilpenicilina G Procaína & $10.000 .000 \mathrm{UI}$ \\
& Benzilpenicilina G Benzatina & $10.500 \mathrm{mg}$ \\
& Sulfato de dihidroestreptomicina & $1.000 \mathrm{mg}$ \\
\hline Mastifin & Piroxicam & $677,00 \mathrm{mg}$ \\
\hline \multirow{2}{*}{ Gentatec } & Sulfato de gentamicina & $40 \mathrm{mg}$ \\
& Gentamicina (como sulfato) & $250 \mathrm{mg}$ \\
\hline Terramicina & Gentamicina & $20,0 \mathrm{~g}$ \\
\hline Tetradur & Oxitetraciclina (dihidratada) & $30 \%$ \\
\hline \multirow{2}{*}{ Tribissen } & Diidrato de oxitetraciclina & \\
& Trimetoprima & $20.000 .000 \mathrm{U.I}$ \\
Agrovet plus & Sulfadiazina & $8,0 \mathrm{~g}$ \\
& Benzilpenicilina procaína & $0,6 \mathrm{~g}$ \\
\hline
\end{tabular}

A infusão intramamária de antibiótico de longa duração no momento da secagem (terapia de vaca seca) é um componente essencial de um programa de controle de mastite na fazenda. Essa terapia ajuda a curar 50\% da mastite causada por Staphylococcus aureus e $80 \%$ dos estreptococos ambientais (Streptococcus uberis e Streptococcus dysgalactiae). Um quarto infectado tratado e curado no período seco vai produzir cerca de $90 \%$ do seu potencial na próxima lactação (Botaro \& Santos; Wattiaux, 2014). Dos antibióticos utilizados, $60 \%$ foram prescritos por médico veterinário e $40 \%$ por vendedores de loja de produtos agrícolas. Todos os entrevistados afirmaram que o leite produzido durante o tratamento com antibióticos tem como destino a comercialização, mas eles não indicam se eles aguardam o período de carência evitando que excedam o limiar de perigo, garantindo assim segurança ao consumidor final. 
O leite pode ser contaminado por medicamentos, antimicrobianos e/ou carrapaticidas, quando não respeitado o período de quarentena específico após a administração de tais medicamentos. Durante a quarentena, o leite não deve ser aproveitado ou comercializado, pois os resíduos presentes podem ocasionar reações alérgicas e até resistência antimicrobiana. Se usado para elaboração de derivados, poderá interferir no processo de fermentação de queijos e iogurtes (Takahashi et al., 2012).

O procedimento padrão para avaliar a segurança dos contaminantes químicos no alimento para consumo humano na União Europeia é definido pela ingesta diária aceitável - IDA e seu estabelecimento se dá a partir da determinação do nível no qual não há efeito observável - NOEL e a aplicação de um fator de segurança adequado (Andreotti \& Nicodemo, 2004). A IDA pode também ser calculada usando dados farmacológicos ou microbiológicos dos níveis de efeitos não farmacológicos observados. A identificação do perfil de resíduos e seu declínio no animal tratado embasa a definição dos limites máximos de resíduos LMRs, o qual serve para proteger o consumidor em relação à antibióticos e são fixados tomando como base dados relevantes de toxicologia, incluindo informações sobre absorção, distribuição, metabolismo e excreção.

Em gado de leite, a mastite bovina é não somente responsável pela maior parte do uso de antibióticos como também a causa de aparecimento de resíduos de antibióticos no leite (Brito \& Lange, 2005; Silva et al., 2013). Após a análise do questionário aplicado junto aos proprietários e/ou gerente das propriedades estudadas, procedeu-se a análise das amostras de leite que foram coletadas. Das 18 amostras analisadas, apenas a amostra de uma propriedade foi positiva para antibióticos $\beta$-lactâmicos e para a tetraciclina todas as amostras foram negativas.

A interpretação dos resultados se faz a partir de uma Guia de interpretação (Figura 6) que fica afixado à parede, próximo ao local de análise, sendo assim, utiliza-se a linha do meio como linha de controle e a partir dela toda a linha de teste com a cor mais clara ou sem formação de nenhuma coloração rósea/vermelha indica resultado positivo para o grupo de antibiótico correspondente (tetraciclina para a linha superior e $\beta$-lactâmicos para a linha inferior ao grupo controle).

Conforme pode ser observado na Figura 7 as fitas que apresentam ausência de coloração na parte inferior confirmam a presença de $\beta$-lactâmicos nas amostras de leite oriundas de uma propriedade estudada.

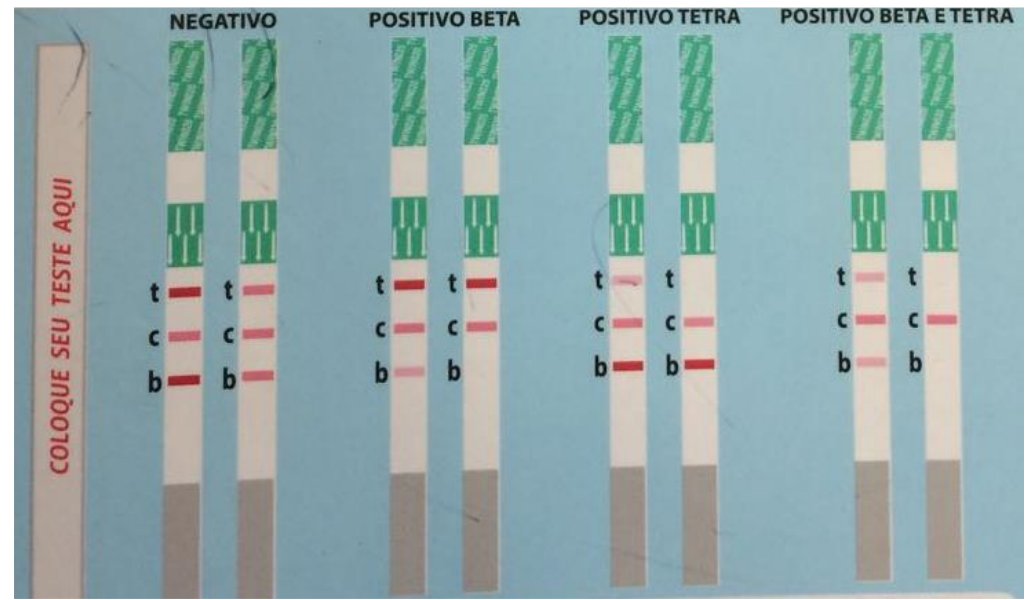

Figura 6. Guia de interpretação de resultados Twinsensor BT ${ }^{\circledR}$

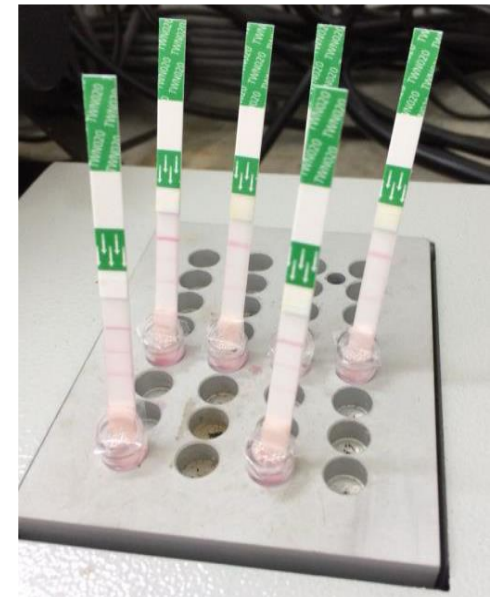

Figura 7. Resultado do teste de antibiótico TwinSensor BT ${ }^{\circledR}$

Segundo o Ministério da Agricultura Pecuária e Abastecimento (BRASIL, 2011), animais que estejam sendo sujeitos ao tratamento com drogas e medicamentos de uso veterinário em geral, passíveis de eliminação pelo leite, precisam ser afastados da produção, respeitando o tempo de carência sugerido pelo fabricante, confirmando que os resíduos da droga não sejam superiores aos níveis fixados em normas específicas.

O fato de cinco das seis propriedades não apresentarem resíduos de antibióticos indica que esses proprietários respeitam o prazo de carência estabelecidos pelo Ministério da Agricultura Pecuária e Abastecimento. 


\section{Referências bibliográficas}

Andreotti, R., \& Nicodemo, M. L. F. (2004). Uso de antimicrobianos na produção de bovinos $e$ desenvolvimento da resistência. (pp. 1-50). Embrapa Gado de Corte.

Araujo, G. B., Santos, H. A., Farias, C. E., Viana, D. A. F., Vieira, E. S., \& Fraga Júnior, A. M. (2015). Detecção de resíduo de antibiótico em leite in natura em laticínio sob inspeção federal. Scientia Plena, 11(4), 4-9.

ABNT - Associação Brasileira de Normas Técnicas. NBR 5426/85: Planos de amostragem e procedimentos na inspeção por atributos. Rio de Janeiro: ABNT, 1985.

Botaro, B. \& SANTOS, M. V. Conhecendo melhor a mastite ambiental - Parte 1 [on-line]. Disponível em: https://www.milkpoint.com.br/radar-tecnico/qualidade-do-leite/conhecendo-melhor-a-mastite-ambientalparte-1-47844n.aspx. Radar Técnico, 2008. Acessado em: 10/12/2017.

Brito, M., \& Lange, C. C. (2005). Resíduos de antibióticos no leite. Embrapa Gado de LeiteComunicado Técnico.

Costa, E. O. (1996). Resíduos de antibióticos no leite: um risco à saúde do consumidor. Higiene Alimentar, 10(44), 15-17.

Erskine, R. J., Walker, R. D., Bolin, C. A., Bartlett, P. C., \& White, D. G. (2002). Trends in antibacterial susceptibility of mastitis pathogens during a seven-year period. Journal of Dairy Science, 85(5), $1111-1118$

FAO. Food and Agriculture Organization. Milk and dairy products in human nutrition. Rome; 2013 in: SBAN. A importância do consumo de leite no atual cenário nutricional brasileiro, 2015

Fagan, E. P., Jobim, C. C., Calixto Júnior, M., Silva, M. S., \& Santos, G. T. (2010). Environmental and handling factors on the chemical composition of milk in dairy farms of Paraná State, Brazil. Revista Brasileira de Zootecnia, 32(3), 309-316. https://doi.org/http//dx.doi/org/10.4025/actascianimsci.v32i3.8570.

Korb, A., Brambilla, D. K., Teixeira, D. C., \& Rodrigues, R. M. (2011). Riscos para a saúde humana do uso de antibióticos na cadeia produtiva leiteira. Revista de Saúde Pública de Santa Catarina, 4(1), 21-36.

Leira, M. H., Botelho, H. A., Barreto, B. B., Botelho, J. H. V., \& Pessoa, G. O. (2018). Fatores que alteram a produção e a qualidade do leite: Revisão. PUBVET, 12(5), 1-13.

Porto, P. P., Deresz, F., Santos, G. T., Lopes, F. C. F., Cecato, U., \& Cóser, A. C. (2009). Milk production, milk composition, intake and digestibility of tropical forages under intermittent grazing system. Revista Brasileira de Zootecnia, 38(8), 1422-1431. https://doi.org/10.1590/S151635982009000800005

Silva, D. P., Gellen, L. F. A., Silva, T. S., da Luz Costa, J., Silva, A. L. L., \& Scheidt, G. N. (2013). Resíduos de antibiótico em leite: prevalência, danos à saúde e prejuízos na indústria de laticínios. Evidência, 13(2), 137-152.

Takahashi, F. H., Cassoli, L. D., Zampar, A., \& Machado, P. F. (2012). Variação e monitoramento da qualidade do leite através do controle estatístico de processos. Ciência Animal Brasileira, 13(1), 99107.

Wattiaux, M. A. Mastite: prevenção e detecção. Essenciais em gado de leite, BabcockInstitute. Disponível em: < http://babcock.wisc.edu/pt-br/node/145>. Acesso em 01 de outubro de 2017.

Recebido: 17 de fevereiro, 2020.

Aprovado: 23 de março, 2020.

Disponível online: 22 junho, 2020.

Licenciamento: Este artigo é publicado na modalidade Acesso Aberto sob a licença Creative Commons Atribuição 4.0 (CC-BY 4.0), a qual permite uso irrestrito, distribuição, reprodução em qualquer meio, desde que o autor e a fonte sejam devidamente creditados. 